\title{
A Rare Upper Gastrointestinal Leech Infestation Causes Massive Bleeding in a 17-Month-Old Boy Admitted to Keren Zonal Referral Hospital, Keren, Eritrea
}

\author{
Filmon Ghebretsadik $^{\mathbb{1}}$, Adam Dawoud Abakar $^{2}{ }^{\mathbb{D}}$, Khalid Abdelsamea Mohamedahmed $^{3 * \mathbb{D}}$ \\ ${ }^{1}$ Department of Internal Medicine, Keren Zonal Referral Hospital, Keren, Eritrea \\ ${ }^{2}$ Department of Medical Parasitology, Faculty of Medical Laboratory Science, University of Gezira, Wad Medani, Sudan \\ ${ }^{3}$ Department of Hematology and Immunology, Faculty of Medical Laboratory Science, University of Gezira, Wad Medani, \\ Sudan
}

\begin{abstract}
Introduction: Leeches are blood-sucking hermaphroditic parasites. They have been used for medicinal purposes for many decades. However, the ingestion and attachment of this parasite to the nasopharynx or upper esophagus were reported to cause constant bleeding, which can be life-threatening if not correctly diagnosed and controlled in places where the water is infested with leech.

Case Presentation: In this study, a 17-month-old boy with serious gastrointestinal bleeding, epistaxis, dry cough, melena, and severe anemia causing cardiorespiratory disturbance presented to our unit has been reported. Severe normocytic normochromic anemia with leukocytosis was revealed by hematologic investigations. Initial investigations revealed no cause for it. The patient received multiple transfusions of Erythrocyte suspension along with other supportive interventions. Despite all the steps, the bleeding continued until the fourth day of entry, when a $7 \mathrm{~cm}$ long leech was removed from the oropharyngeal region. The bleeding ceased immediately after the removal of the leech and the patient was released from the hospital in decent health later.

Conclusion: In areas where epistaxis, hematemesis, gastrointestinal bleeding, and severe anemia are of uncertain cause, leech infestation should be considered.

Keywords: Upper gastrointestinal bleeding, Leech infestation, Massive bleeding, Anemia
\end{abstract}

Received: October 10, 2019, Accepted: February 18, 2020, ePublished: April 1, 2020

\section{Introduction}

An infrequent cause of the referral of children to medical centers is upper gastrointestinal bleeding. In children, primary acid peptic diseases are not common causes of upper gastrointestinal bleeding; however, in this age group, secondary types are caused by drugs, mainly acetylsalicylic acid (ASA), or systemic disorders, and esophageal varicose veins are more common due to portal hypertension. Foreign body ingestion, corrosive material ingestion and Mallory-Weiss syndrome are also uncommon causes of acute upper gastrointestinal bleeding in children (1). Leech endoparasitism is unusual, as a cause of hematemesis and vomiting (1-6). Bleeding can be chronic or sporadic due to the presence of anticoagulants in leech saliva (1-6). Leeches are rare endoparasites that suck blood and survive in polluted water and can cause possible fatal complications $(7,8)$. In this report, we describe a rare case of massive gastrointestinal (GI) bleeding and severe anemia associated with a leech infestation.

\section{Case Presentation}

A 17-months-boy, coming from a place called Shieb Seleba, referred to the Emergency Department of Keren Zonal Referral Hospital, located in the second biggest city of Eritrea, Keren. The child presented with a 4-day history of vomiting of bloody material which was preceded and accompanied by epistaxis, dry cough, and passage of tarry stool. The child was circumcised at 1 month of age and underwent uvulectomy when he was 1 year old, with no report of bleeding or coagulation problems. Additionally, there was no family history of bleeding tendency.

On evaluation, he was in pain with a temperature of $38.4^{\circ} \mathrm{C}$, respiratory rate of 66 breaths $/ \mathrm{min}$, heart rate of 156 beats/min, and an oxygen saturation of $89 \%$. Clinical signs included mucosal, skin and palmar pallor. His development and motor growth were natural (weight, height, and percentiles). An evaluation of his throat 
revealed fresh blood in the oral cavity. Auscultation of the lungs was performed, and there were indrawings in the bilateral chest wall. Further examination showed no other abnormalities. No other apparent bleeding site, hepatosplenomegaly, or lymphadenopathy, in particular, was found.

A complete blood count showed 37160 WBC/ $\mathrm{uL}$ with $33.21 \%$ neutrophils, $52.91 \%$ lymphocytes, and $0.16 \%$ eosinophils. At the hematocrit level of $11.2 \%$, mean corpuscular volume of $92 \mathrm{fl}$, and red cell distribution width of $20.7 \%$, hemoglobin was observed to be $3.25 \mathrm{~g} / \mathrm{dL}$. The platelet count was $306000 / \mathrm{uL}$. With normocytic normochromic erythrocytes, the peripheral blood smear was normal. No hemoparasite was detected in the examination of the blood film. It was common to have a basic metabolic panel and urine analysis. Coagulation testing could not be carried out, but the time for bleeding and clotting was natural. The diagnosis of severe normocytic anemia after major upper gastrointestinal bleeding (UGIB) was made on the basis of these hypotheses. The boy was diagnosed with serious pneumonia as well.

The boy was treated with intravenous hydration of isotonic saline, administration of supplemental oxygen by mask, and transfusion of erythrocyte suspension (15 $\mathrm{mL} / \mathrm{kg}$ ). Wide-spectrum intravenous antibiotics and intravenous $\mathrm{H} 2$ antagonists have also been initiated thereafter. It was not possible to determine a specific reason for UGIB until the fourth day of admission when a $7 \mathrm{~cm}$ long dark brown colored parasite that appeared to be a leech (Figure 1) was removed from the oropharynx of the patient and bleeding stopped shortly after the procedure. On the sixth day of entry, after 4 erythrocyte suspension transfusions, the hemoglobin level increased to $82 \mathrm{~g} / \mathrm{dL}$ (Table 1). After a close investigation, it was revealed that there was a body of water running through the village where the people and their family lived and used the water without any safety for drinking and everyday use. Three days later, the patient was released and given an oral iron supplement. The boy did not

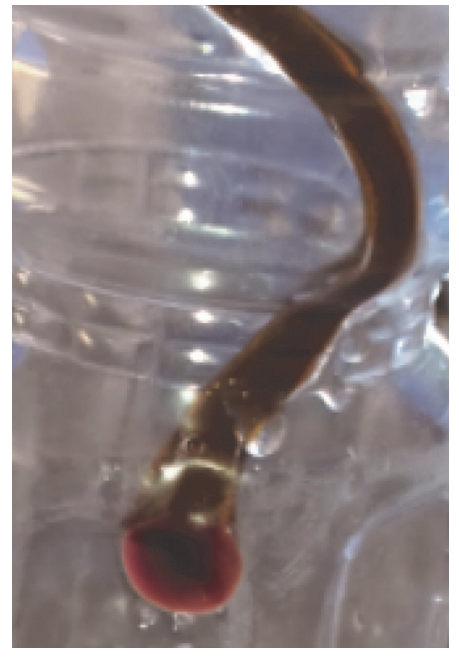

Figure 1. Photograph of the Leech after Removal.

show any additional bleeding, including hematemesis or epistaxis, after 3 weeks of follow-up. Moreover, no other leeches were observed.

\section{Discussion}

Leeches belong to the phylum Annelida and comprise the class Hirudinea. They are carnivorous, hermaphroditic, and segmented worms. Aquatic leeches can live in either freshwater or saltwater where humans can meet them, such as lakes, ponds, mud, and sand (2,5-7). For a number of disorders, including dermatological infections, reproductive system issues, inflammation, and venous obstruction, leeches have been used for medicinal purposes for many decades. However, they may also cause diseases such as internal hirudiniasis that may present with cough, hemoptysis, epistaxis, hematemesis, melena, dysphagia, hoarseness, and dyspnea $(3,5)$. People drink water from lakes, springs, and streams that could be leech-infested in rural areas of developing countries where hygiene is poor. Bathing in infected environments may be followed by the attachment of this parasite to the skin or its penetration into normal body orifices (1).

Table 1. The Results of $\mathrm{CBC}$ before and after the Treatment

\begin{tabular}{lcccc}
\hline Test & At Admission & $\begin{array}{c}\text { At the 2nd Day } \\
\text { (Following 2 Blood } \\
\text { Transfusions, } \mathbf{1 5} \mathbf{~ m L / k g )}\end{array}$ & $\begin{array}{c}\text { At the 4th Day } \\
\text { (Following 3 Blood } \\
\text { Transfusions) }\end{array}$ & $\begin{array}{c}\text { At the 6th Day (Following } \\
\text { 4 Blood Transfusions) }\end{array}$ \\
\hline $\mathrm{WBC} \times 10^{3}$ & 37.16 & 28.34 & 14.67 & 11.4 \\
After 3 Weeks of Follow-up
\end{tabular}


The nose, nasopharynx, oropharynx, larynx, and rectum have been identified as internal infestation sites (1-3). Cases of vaginal, ocular, and tracheal hirudiniasis were rarely reported (3-5). While the clinical effects of leech infestation rely on the precise location of the infestation, nasal infestation and repeated unexplained epistaxis are the typical presentations of leech endoparasitism. Massive hematemesis as a complaint in patients, especially in the pediatric age group, was reported in very few studies. Hirudin is anticoagulant agent secreted by leeches which makes the wound bleed more than expected, and even after the worm is removed, it may continue (3,5-7). A complete history and a thorough review accompanied by sufficient investigation were included in the approach to a patient with leech infestation. The remedy was to kill the leech as quickly as possible to avoid complications (1-7).

The presenting signs included severe anemia, epistaxis, abundant hematemesis, pallor, melena, and cardiorespiratory pain in our patient. Despite prolonged bleeding, the diagnosis was deferred because leech infestation in this age group is extremely unforeseen. The baby presumably swallowed the leech while playing on the beach, swimming in the sea, or soaking up drinking water from the stream.

\section{Conclusion}

In conclusion, although leech infestation is an uncommon cause of profuse hematemesis, it should be considered in cases of unknown hemoptysis, epistaxis, and gastrointestinal bleeding, especially in regions that are characterized by a high incidence of leech infestation. It is important to consider leeches in the differential diagnosis of severe anemia. Furthermore, precautions for the safety of water (filtering, boiling, applying chloride, etc.) should be encouraged and conducted in leech-endemic regions in addition to providing comprehensive public education programs.

\section{Conflict of Interests}

The authors have declared that no conflict of interests exists.

Ethical Issues

In this study, ethical considerations have been fully observed.

\section{Acknowledgments}

The cooperation of the staff of the clinic and laboratory of Keren Zonal Referral Hospital is hereby appreciated.

\section{Authors' Contribution}

FGW designed the study and did data collection. FGW, ADA, and KAM did writing of the case report. KAM and ADA did editing and reviewing of the case report.

\section{Funding}

The authors received no financial support for the case report from any funding agencies.

\section{References}

1. Haghighat M. An unusual presentation of leech leading to severe hematemesis in an infant. MJIRI. 1997;11(3):249-250.

2. Mustafa T, Selahattin K, Hulya B. An Unusual Cause of Gastrointestinal Bleeding and Severe Anemia in a Child: Leech Infestation. J Trop Pediatr. 2009;55(5):338-339. doi. org/10.1093/tropej/fmp015

3. Moslehi MA, Imanieh MH, Adib A. Bronchial Leech Infestation in a 15-year-old female. Case Rep Pediatr. 2016;2016:2372686. doi: 10.1155/2016/2372686

4. Mandana R, Yalda Jabbari-M. intermittent gastrointestinal bleeding in a child: leech infestation. Iran J Pediatr. 2012;22(4):572-573.

5. Farrar J, Hotez P, Junghanss T, Kang G, Lalloo D, White N. Manson's Tropical infectious diseases. 23th Edition. USA: Saunders Ltd; 2013.

6. Burak $U$, Serif $Y$. A rare cause of respiratory distress and hemopytsis: Laryngeal leech infestation. Pak J Med Sci. 2012;28(3):543-545.

7. Shitaye N, Shibabaw S. Severe anemia due to pharyngeal leech infestation; a case report from Ethiopia. BMC Surg. 2017;17:102. doi:10.1186/s12893-017-0298-7.

8. Zengin $Y$, Gündüz $E$, İçer $M$, Dursun $R$, Durgun $H M$, Gündüzalp A, Ekinci M. A rare cause of Epistaxis due to leech infestation. J Acad Emerg Med Case Rep. 2014;5:197-199. doi: 10.5152/JAEMCR.2014.181 creativecommons.org/licenses/by/4.0), which permits unrestricted use, distribution, and reproduction in any medium, provided the original work is properly cited. 